\title{
História Militar de Angola: uma obra colectiva pioneira que marca uma época
}

\section{Virgílio Coelho}

\section{Q OpenEdition}

1 Journals

\section{Edição electrónica}

URL: https://journals.openedition.org/mulemba/449

DOI: $10.4000 /$ mulemba.449

ISSN: 2520-0305

\section{Editora}

Edições Pedago

\section{Edição impressa}

Data de publição: 1 maio 2015

Paginação: 515-524

ISSN: 2182-6471

\section{Refêrencia eletrónica}

Virgílio Coelho, «História Militar de Angola: uma obra colectiva pioneira que marca uma época»,

Mulemba [Online], 5 (9) | 2015, posto online no dia 27 novembro 2016, consultado o 21 setembro 2021 URL: http://journals.openedition.org/mulemba/449 ; DOI: https://doi.org/10.4000/mulemba.449

Este documento foi criado de forma automática no dia 21 setembro 2021.

Tous droits réservés 


\title{
História Militar de Angola: uma obra colectiva pioneira que marca uma época
}

\author{
Virgílio Coelho
}

\section{NOTA DO AUTOR}

Texto da apresentação pública da obra coordenada por Miguel JÚNIOR e Manuel Maria DIFUILA, História Militar de Angola. Luanda, Editorial Kilombelombe, 2015, 290p.

[«Ciências Humanas e Sociais - Série História de Angola»; 13], que teve lugar em Luanda, no dia 07 de Abril de 2015, pelas 17h00, no Memorial Dr. António Agostinho Neto.

1 Constitui para nós uma grande honra e prazer estar hoje, aqui e agora, para apresentar a obra História Militar de Angola, o resultado de um projecto de pesquisa da Direcção de Estudos e Investigação Militar (DEIM) do Estado Maior General das Forças Armadas Angolanas (EMG-FAA), do qual resulta esta primeira obra que agora vê a luz do dia, num período extraordinário e paradigmático de duplo alcance: por um lado, porque celebrámos há poucos dias o décimo terceiro ano da Assinatura dos Acordos de Paz de Lwena, na província do Moxico, e que determinou o fim de um longo período de 27 anos de guerra fratricida, que dilacerou vidas humanas, destruiu bens e manteve durante muito tempo os filhos desta terra desunidos; e por outro, porque este ano celebramos em todo o território nacional 40 anos da proclamação da nossa Independência Nacional, uma evidência que nos orgulha e nos impulsiona no sentido da unidade e da aspiração dos valores de uma Pátria unida de Cabinda ao Cunene e do mar ao leste, Pátria que todos nós muito queremos e por ela nutrimos os maiores e melhores sentimentos. $\mathrm{E}$ como não há duas sem três, que nos seja permitido realçar o lugar onde aqui nos encontramos para celebrar este acto e lembrar a memória do saudoso Presidente António Agostinho Neto, Herói Nacional, lutador incansável e destemido combatente pelos ideais da Pátria, o fundador do Estado Angolano no dia 11 de Novembro de 1975 e 
um dos grandes promotores da ideia de Nação Angolana, que todos nós almejamos construir.

2 Não podemos deixar de expressar a nossa incontida alegria e agradecimento ao General Miguel Júnior, pelo convite que nos endereçou para apresentar esta obra, o que o fazemos na nossa qualidade de Coordenador da colecção "Ciências Humanas e Sociais» da Editorial Kilombelombe, organismo editor desta obra, que vem enriquecer a «Série História de Angola», já de si tão rica de títulos e autores antes publicados e que nos permite realçar o seu real valor no contexto dos demais títulos.

História Militar de Angola é uma obra colectiva, que é coordenada pelo General Miguel Júnior e pelo professor Manuel Maria Difuila, ambos historiadores e académicos reconhecidos publicamente, e integra ainda o contributo dos historiadores António Edilson Wanadumbo, António Borges Paquisse, Maria Quarta Mpunza, Silvestre António Francisco, Pungula Fernando Manuel, Joaquim Rufino Mbeça França e Justino da Glória Ramos, todos militares de carreira integrados na DEIM do EMG-FAA. Convém realçar antes de mais nada, e tal como veremos adiante, a indicação destes coautores tal como o acabamos de o fazer, obedece unicamente ao critério de integração dos mesmos nos oito capítulos que compõem a obra e não outro.

De acordo com a nota introdutória dos seus Coordenadores, esta obra constitui uma iniciativa das Forças Armadas Angolanas (FAA) e tem por fim dotá-la de um instrumento que possa constituir uma referência sólida em termos de conhecimentos atinentes ao percurso histórico e militar de Angola, com o intuito de tornar possível o entendimento e o seu estudo em todos os níveis. Trata-se, sem dúvida nenhuma, de uma obra nascida de um programa pioneiro que nos deve orgulhar, primeiro pela iniciativa e pelo risco que se corre por se ser primeiros a efectuar um esboço geral da nossa história militar devidamente enquadrada no contexto mais geral da História de Angola; segundo porque ao se exporem aberta e claramente à crítica, os seus promotores abrem caminho à avaliação geral e à possibilidade de enriquecimento deste pequeno manual há muito esperado não apenas no círculo militar, mas também desejado por todos quantos se interessam pela História de Angola.

Segundo ainda os Coordenadores, a organização da obra está dividida em quatro partes e integra oito capítulos. A primeira parte da obra, que cobre o período do século XVI ao século XIX, ocupa os capítulos I e II, e nele intervêem Miguel Júnior, com o texto intitulado "A guerra na África Central Ocidental, do século XVI ao século XIX» (pp. 23-106) e António Adilson Wanadumbo, com o trabalho "As aç̧ões militares para a ocupação efectiva: 1850-1900» (pp. 107-122); a segunda parte, que engloba o século XX, inclui os capítulos III e IV, com os textos de António Borges Paquisse, «A resistência ao colonialismo português: 1900-1940» (pp. 123-141) e Maria Quarta Punza, «A organização militar colonial e a guerra: 1940-1974» (pp. 143-165); a terceira parte, que integra os capítulos V, VI e VII, inclui os trabalhos de Silvestre António Francisco, «A guerra de guerrilha do MPLA: 1961-1974» (pp. 167-200), Pungula Fernando Manuel, «A guerra de guerrilha da UPA/ FNLA» (pp. 201-219) e de Joaquim Rufino Mbeça França, «A guerra de guerrilha das FALA: 1965-1974» (pp. 221-251), respectivamente; e, finalmente, a quarta parte que integra o capítulo VIII, regista o trabalho de Justino da Glória Ramos, sobre «A guerra interna: 1975-1991» (pp. 253-285). Como se poderá observar, apesar dos múltiplos autores, esta obra trata de forma sequencial a história dos factos militares e da guerra no nosso país de uma forma unívoca e em capítulos cujos temas são complementares. 
6 Em trabalhos deste tipo, apesar da tentativa de se procurar conciliar as datas e respectiva integração em períodos enquadrados em capítulos, muitas vezes, é comum observar-se que no afã de descrever e de explicar, algumas datas extravazam os períodos previamente indicados, pelo que, a presente obra também não foge a isso; deste modo, quando isso ocorre, o leitor deve entendê-lo como uma riqueza expressa pelos materiais tidos em presença e pelo afã que leva cada autor a utilizá-los amplamente, no sentido de dar coerência e consistência à sua exposição.

Pela sua importância e extensão, o capítulo I constitui sem qualquer dúvida a parte de leão da presente obra. De acordo com Miguel Júnior, o seu autor, ele «[...] tem a ver com os primórdios da nossa história militar» e esta está indissociavelmente ligada «[...] às histórias dos reinos da África Central Ocidental, que mais tarde integraram o espaço de Angola. Por esse facto, a história desses reinos é naturalmente parte integrante da história de Angola», sendo, por isso, «[...] indispensável valorizar o conjunto de informações relativas às histórias das guerras dos povos da África Central Ocidental e é imprescindivel perceber as dinâmicas que envolveram o mundo, para entendermos que as guerras que tiveram lugar entre os séculos XVI $e$ XIX foram produto das conjunturas vivenciadas e da própria natureza dos sistemas mundiais» (JÚNIOR 2015: 25). Para entender essas guerras, Miguel Júnior organizou este capítulo de forma a analisá-lo em duas partes: na primeira, procurou estudar os factos e os fenómenos ocorridos durante os séculos XVI-XVII; na segunda, os séculos XVIII e XIX.

8 Para compreender tanto um período como o outro, Miguel Júnior tratou inicialmente de se dotar de algumas noções operativas, no âmbito de uma aparelhagem conceptual sóbria, a saber, tratou de começar por definir o contexto espacial da área a estudar que, para o caso, a região que posteriormente viria a dar a noção territorial de Angola, que tem sido apontada e enquadrada no contexto da África Central Ocidental, pelos historiadores que se ocupam do estudo das realidades em referência. Neste sentido, através de uma análise fina e concreta, critica a forma como têm sido estudadas as realidades históricas africanas e, com isso, procurou evitar a confusão metodológica e periodológica das mesmas, uma vez que, «[...] a grande verdade é que a génese africana remonta o próprio século XVI, o que significa dizer que as comunidades africanas tinham vida e dinâmicas muito próprias e um certo estádio de desenvolvimento", factos que põem em causa, por exemplo, a noção ou a «expressão história pré-colonial», com a qual estamos de pleno acordo e assim pensando, nos posicionamos tal como já o fez anteriormente Catherine Coquery-Vidrovitch, eminente historiadora francesa, quando escreve:

«Em história, é necessário evitar a expressão “África pré-colonial”. Ela conjectura e projecta no passado um estado e processos que ocorreram posteriormente na história do continente, e para os quais os Africanos de antigamente não faziam a mínima ideia. A quase totalidade das regiões africanas não estiveram, até muito recentemente, colonizados por potências exteriores ao continente (exceptuando o Egipto, conquistado pelos Gregos e colonizado pelos Romanos, e na costa oriental da África, colonizada no século XIX pelo sultanato de Omã depois de Zanzibar). Ao contrário, algumas dentre elas foram colonizadas por outros povos africanos (é igualmente isso o que se passou nos outros continentes). Mas, na sua imensa maioria, estas regiões mantiveram-se independentes vis-a-vis com os Europeus até ao fim do século XIX, incluindo durante o período do tráfico atlântico (há, no entanto, excepções, como o porto de Luanda, ocupado continuamente pelos Portugueses depois do século XVI). Enfim, a independência (em 1956 do Sudão, em 1957 no Ghana, mas apenas em 1963 do Kenya ou em 1990 na Namíbia) não constituiu senão uma novidade para um pequeno número de velhos Africanos 
nascidos antes da colonização (sendo entendido que o processo assim qualificado não tenha grande coisa a ver com as independências anteriores)» ${ }^{1}$

Uma vez situados os problemas de base, Miguel Júnior começa por enquadrar a noção e a peridiologia da escravatura entre os séculos IX e XIII, a introdução do mercantilismo europeu em África, a transformação em outros moldes da escravatura de base, o achamento do Brasil em 1500 e a consequente necessidade de mão-de-obra escrava para a sua real colonização e desenvolvimento económico; isso fez com que a procura se efectivasse muito justamente na região da África Central Ocidental, que passou a ser a principal fornecedora da mão-de-obra escrava para o Brasil. Assim, em páginas de apontamentos densos, Miguel Júnior analisa, por um lado, a guerra nos reinos do Kongo (pp. 28-39), do Ndongo (pp. 39- 53), da Matamba (pp. 54-58), de Kasanji, Loango e na Colónia de Benguela (pp. 58-61), durante os séculos XVI e XVII; e por outro, nos Reinos do Kongo (pp. 63-66), do Ndongo e Colónia de Angola (pp. 66-77), Reinos de Matamba e Kasanji (pp. 77-79), Reinos Ovimbundu (pp. 80-85), no Império Lunda e reino Chokwe (pp. 85-88), nos séculos XVIII e XIX. Posteriormente, dedica-se à «noção da arte da guerra na África Central Ocidental», durante os séculos XVI-XX, focando a análise inicialmente nas organizações guerreiras africanas (pp. 89-93) e estuda, posteriormente, a organização militar colonial (pp. 93-96), para, finalmente, efectuar um registo breve sobre «as armas de fogo e sua evolução» (p. 96).

10 A sua pesquisa, ancorada em documentos de arquivo e em trabalhos publicados, fazendo recurso a eminentes estudiosos do tema e espaço concernidos pelo seu estudo, faz do seu trabalho uma base de informação imprescindível para todos quantos se interessem sobre estas questões específicas.

11 Entretanto, o trabalho levado a cabo por António Edilson Wanadumbo complementa o anterior, já que, ao ater-se exclusivamente à segunda metade do século XIX, articula a sua argumentação em dois momentos concretos, a saber: «[...] analisa a situação militar da colónia, [...] as novas dinâmicas políticas $e$ as disputas registadas entre as potências europeias pela posse de territórios africanos. 0 segundo momento examina as principais campanhas militares [promovidas pelos Portugueses] e as resistências africanas à ocupação efectiva do exército colonial português» (WANADUMBO 2015: 109).

A abordagem de Wanadumbo coloca em destaque o projecto colonial português, que, tal como se viu no capítulo anterior, começou a tomar forma com a ocupação pelos portugueses de algumas parcelas territoriais do Reino de Ndongo, passando desde então a evidenciar-se uma nova entidade: a Colónia de Angola, não obstante verificar-se que até a segunda metade do século XIX a influência portuguesa ainda permanecesse mais acentuada no litoral. Até então, a Colónia de Angola era praticamente constituída por feitorias, que, paulatinamente, fora ganhando alguma «base territorial» no hinterland. Até o ano de 1850, a Colónia de Angola compreendia três distritos: Luanda, Benguela e Moçamedes. Em poucos anos foram surgindo outros distritos: Ambriz (1855), Encoje, Bembe e São Salvador, entre 1860 e 1870. Foi a partir da Conferência de Berlim que a ocupação dos territórios em África iria acelerar, através das chamadas «campanhas de pacificação». Este capítulo regista assim essas campanhas e as resistências africanas, que se opuseram nos reinos do Kongo (pp. 115-116), de Kasanji (pp. 116-117), dos Dembos (p. 118), em Seles e Amboim (pp. 118-119), no Reino do Bié (pp. 119-120) e no Humbe (p. 120). resistência ao colonialismo português», no período entre 1900 e 1940, isto é, na "fase final da 
ocupação efectiva do território sob tutela de Portugal», tendo começado por abordar «a situação militar que prevalecia na colónia de Angola no começo do século XX», e, posteriormente, estuda "os momentos mais significativos de resistência em determinados pontos do território e as várias acções e combates que tiveram lugar até 1940» (PAQUISSE 2015: 125). Assim, são aqui estudadas a «resistência Mbalundu» (pp. 126-129), a «resistência dos Dembos» (pp. 129-132), a «resistência dos Kwanyama» (pp. 132-133), a «resistência ao sul do Kwanza» (pp. 134-135), a «resistência do Reino do Kongo» (pp. 135-136), a «resistência dos Reinos Lunda e Tchokwe» (p. 136) e o «fim da autonomia herero» (pp. 136-137). Como se sabe, a questão da resistência levada a cabo pelas múltiplas chefias políticas no território que hoje é Angola ainda está por fazer e, na realidade, este trabalho configura um começo que é necessário aprofundar no futuro.

Tal como o título indica, o objectivo fundamental do trabalho da historiadora Maria Quarta Punza é estudar «a organização militar colonial e a guerra em Angola, no período entre 1940 e 1974». Para fazê-lo, a autora dividiu-o em duas partes; a primeira estuda a organização militar portuguesa no período de 1940 a 1960, «de modo a caracterizar as estruturas militares que existiam em Angola no espaço de tempo em referência e explicar a sua forma de organização» (p. 145). Essa análise, bem documentada, é sobretudo efectuada com base na legislação portuguesa existente (pp. 145-149); em segundo lugar, a autora estuda «o lugar das transformações ocorridas na organização militar colonial, espelhando a sua evolução e o modo como a guerra colonial foi dirigida com o objectivo de conter as guerras de guerrilha, enquanto formas de luta empreendidas pelos movimentos de libertação» (p. 145). Como se pode depreender, essas transformações são efectuadas, sobretudo, a partir do ano de 1961. Mas as suas causas são devidas às ocorrências no terreno da luta em que se evidenciam as sublevações (não armadas, ou, dito de outro modo, políticas, sociais e económicas) efectuadas no distrito de Malanje, no mês de Janeiro 1960, que são motivadas pela greve dos trabalhadores dos campos de cultivo de algodão da COTONANG, na região da Baixa de Cassange, e a respectiva repressão violenta que se lhe seguiu como resposta do governo colonial-fascista. Cerca de um ano depois, no dia 4 de Fevereiro de 1961, um grupo de angolanos politicamente enquadrados em organizações políticas cujos fins pugnavam pela independência nacional, atacam a «casa de reclusão militar [...] quartel da companhia móvel da Polícia de Segurança Pública» e a «cadeia civil da cidade de Luanda», a fim de libertarem os seus companheiros, do chamado «Processo dos 50», que aí se achavam prisioneiros, e «chamar a atenção da imprensa internacional para a situação que se vivia em Angola» (p. 150). Consequentemente, há que se registar também a rebelião armada contra os colonos portugueses lançada no Norte de Angola (São Salvador do Zaire, Dembos, Kwanza-Norte e Uije), no dia 15 de Março de 1961, pela União das Populações de Angola (UPA). Assim, de acordo com Maria Quarta Punza, quando em 1961 se registaram estas ocorrências políticas e militares levadas a cabo pelos angolanos, «a presença militar em Angola era diminuta e débil. [...] 0 dispositivo militar estava limitado aos três regimentos de infantaria presentes em Luanda, Nova Lisboa e Sá da Bandeira [...]» (pp. 150-151) e pouco mais. Foram as sublevações de 1960 e 1961 que levaram os Portugueses a operar uma transformação completa do seu dispositivo militar, pois,

«Apesar do Diploma de Novembro de 1960 ter determinado a constituição de cinco comandos territoriais (Norte, Centro, Sul, Leste e São Tomé e Príncipe) e de uma circunscrição militar (Cabinda), a sua implementação só ocorreu em concreto em 1961» (p. 151). 
Maria Quarta Punza destaca o facto de as forças militares portuguesas terem reagido de modo rápido à sublevação empreendida pelos movimentos de libertação e, ao assim procederem, fizeram-no «de acordo com os planos estratégicos das Forças Armadas Portuguesas, ao longo da guerra colonial», em três fases, a saber: primeira fase, de 1961 a 1966; segunda fase, de 1966 a 1970 e terceira fase, de 1970 a 1974 (pp. 156-157).

Contudo, e para fechar as ideias mestras do seu raciocínio, esta autora destaca também que após o golpe de Estado ocorrido em Portugal no dia 25 de Abril de 1974, e o início do processo de descolonização das então colónias, houve retracção das Forças Armadas Portuguesas (FAP), no sentido de acelerar as suas independências.

Os capítulos V, VI e VII, estudam a guerra de guerrilha levadas a cabo pelos três movimentos de libertação contra a opressão colonial, através das suas estruturas militares. O capítulo V, estudado pelo historiador Silvestre António Francisco, aborda «A guerra de guerrilha do MPLA», no período de 1961-1974 (pp. 167-200); o capítulo VI, que foi escrito por Pungula Fernando Manuel, ocupa-se da «guerra de guerrilha da UPA/ FNLA» (pp. 201-219) e o Capítulo VII, que coube a Joaquim Rufino Mbeça França, estudou «A guerra de guerrilha das FALA: 1965-1974» (pp. 221-251). Nestes estudos, são assim tentados os primeiros esboços de estruturação objectiva sobre os movimentos angolanos de libertação nacional antes jamais visto. Em escrita simples, cada um destes autores procura situar luta travada por cada um dos movimentos de libertação nacional (MPLA, FNLA e UNITA) no contexto deste longo período de luta, a começar pela génese dos exércitos criados, passando pelas principais lutas e problemas encontrados no maquis, mostrando os seus principais objectivos, os problemas internos de cada estrutura, as noções operativas da luta, as estratégias traçadas em cada período da luta e, finalmente, o calar das armas que viria a culminar com a assinatura de acordos parcelares que cada movimento viria a assinar com a então entidade colonizadora.

Esta estruturação mostra bem a importância da presente obra, pois, através destes especialistas da História Militar de Angola, temos assim a possibilidade de seguir ponto por ponto o percurso das lutas de guerrilha que ocuparam os 14 anos da Luta Armada de Libertação Nacional, e que, historicamente, constitui o primeiro período da guerra empreendida pelos movimentos de libertação contra o colonialismo opressor. A informação desses três capítulos cria condições para a compreensão do capítulo seguinte que, numa primeira fase, trata com alguma minúcia a fase da descolonização e da proclamação da independência nacional, e, numa segunda fase, da organização do novel Estado independente e, finalmente, numa terceira parte se descreve a continuação da guerra, período em que são estudadas as batalhas dos anos oitenta até ao ano de 1991, e cujo desfecho levar-nos-ia à conquista da Paz.

De acordo com os organizadores, o decénio 1992-2002 não cabe neste livro, pois, será objecto de estudo minucioso e parcelar posterior. Esse último capítulo de que vínhamos falando, denomina-se «A guerra interna: 1975-1991» (pp. 253-285) e foi escrito por Justino da Glória Ramos.

Entretanto, o facto destes estudos se ancorarem em abordagens promovidas por investigadores profissionais, não obstante a obra ser considerada «um modesto contributo» (p. 18), que ainda não «esgota o manancial de informações certamente ainda disponíveis sobre o assunto» (p. 18), ela vem em boa hora para colmatar uma falha que já se fazia sentir há muito tempo, tal como tão bem o expressa o seu prefaciador, o General Geraldo Sachipengo Nunda, quando lembra que «[...] ela colmata o vazio que se 
fazia sentir no seio das Forças Armadas Angolanas e representa um meio para se aprofundar o conhecimento a respeito da história militar de Angola» (p. 15).

Estão, pois, de parabéns os seus coautores e respectivos coordenadores, mas também, como não poderia deixar de ser, todos quantos tornaram possível este grande empreendimento, da qual se destaca o Departamento de Estudos e Investigação Militar (DEIM) do Estado Maior General das FAA.

\section{NOTAS}

1. Cf. COQUERY-VIDROVITCH Catherine, Petite Histoire de l'Afrique. L'Afrique au Sud do Sahara de la préhistoire à nos jours. Paris, La Découverte, 2011, p. 10. [Tradução minha, VC].

\section{AUTOR}

\section{VIRGÍLIO COELHO}

virgiliocoelho@hotmail.com virgiliocrcoelho@gmail.com

Professor Auxiliar do Departamento de Antropologia (DA) da Faculdade de Ciências Sociais (FCS) da Universidade Agostinho Negto (UAN).

Professor Auxiliar do Departamento de Antropologia (DA) da Faculdade de Ciências Sociais (FCS) da Universidade Agostinho Neto (UAN), é antropológo, diplomado pela École Pratique des Hautes Études (EPHE), Universidade de Paris - Sorbonne (França), tendo apresentado a tese intitulada La place des jumeaux dans le système religieux des Ndongo (Ambundu), Angola (523p.), onde também efectuou estudos doutorais em Antropologia Social e Cultural, sob a direcção do Prof. Doutor Michel Cartry. Concluiu o mestrado: Diplôme d'études approfondis (DEA), na especialidade de «Anthropologie comparée des Religions d'Afrique, d'Orient et d'Extreme Orient», em 1988, sob a direcção da Prof. a Doutora Jacqueline Duvernay-Bolens, tendo submetido a tese Le culte des «génies» ítùtà chez les Ndongo de la valée du Kwanza, Angola (176p.). É investigador (Assessor Principal) do Ministério da Cultura, onde dirigiu algumas das suas instituições, dentre as quais o Departamento de Folclore da Direcção Nacional de Arte (DINARTE) e a Delegação Provincial de Luanda (DPL). De Janeiro de 2003 a Setembro de 2008, foi Vice-Ministro da Cultura para o Património e a investigação científica, no âmbito do Governo de unidade e reconciliação nacional (GURN). No âmbito do ensino, é docente no curso de Antropologia do Departamento de Antropologia da Faculdade de Ciências Sociais (FCS) da Universidade Agostinho Neto (UAN), orientando formação nas cadeiras seguintes: Introdução à Antropologia; Etnologia Geral; Semiótica e Semiologia; Tradições Orais, Mitos e Mitologias; Antropologia das Religiões; Epistemologias Antropológicas e Teorias 
Antropológicas. As suas principais áreas de investigação são a antropologia social e cultural (estudos de parentesco e de organização social), de antropologia política (questões específicas sobre a problemática do Estado em África, nação, etnia e etnicidade, tribo, identidade cultural e alteridades, etc.), de antropologia do simbólico, antropologia histórica, antropologia e geografia linguística e de antropologia da literatura e artes em Angola; e ainda, a antropologia das religiões em África (África central, oriental e austral, particularmente em Angola). É membro correspondente da Academia das Ciências de Lisboa, membro da Associação de Antropólogos e Sociólogos de Angola (AASA), onde desempenha as funções de Secretário do Pelouro de Pesquisas e Conferências do seu Comité Executivo e vice-presidente do Conselho Editorial e Secretário da Ngola - Revista de Estudos Sociais da AASA; na sua qualidade de artista plástico, é membro fundador da União Nacional dos Artistas Plásticos (UNAC), tendo dirigido a sua Mesa da Assembleia Geral no período de 2005 a 2009; e membro da União dos Escritores Angolanos (UEA). Jornalista, desempenhou funções no suplemento dominical Vida \& Cultura (e posteriormente Vida Cultural) do Jornal de Angola e foi coordenador da secção «Cultura» do jornal Angolense e, posteriormente, do jornal Semanário Angolense. É actualmente Director das Edições Mulemba, editora da FCS da UAN e editor das seguintes revistas: Mulemba - Revista Angolana de Ciências Sociais, órgão científico da FCS da UAN; Maka - Revista de Literatura \& Artes, da União dos Escritores Angolanos (UEA) e Ngola - Revista de Estudos Sociais, órgão da Associação de Sociólogos e Antropólogos de Angola (AASA), integrando os seus conselhos científicos e editoriais. É igualmente membro dos Conselhos Científicos das revistas seguintes: África - Revista do Centro de Estudos Africanos da Universidade de São Paulo (Brasil), Cadernos de Estudos Africanos, revista do Centro de Estudos Africanos do ISCTE - Instituto Superior das Ciências do Trabalho e da Empresa (Lisboa, Portugal), e do Conselho Editorial da RAS - Revista Angolana de Sociologia, da Sociedade Angolana de Sociologia (SAS). Em 2010 foi-lhe outorgado o «Prémio Nacional de Cultura e Artes», na secção de Ciências Humanas e Sociais, pelas obras «Em busca de Kábàsà!...» Estudos e reflexões sobre o «Reino» do Ndòngò. Contribuições para a História de Angola e Os Túmúndòngò, os «génios» da natureza e o Kílàmbà. Estudos sobre a sociedade e a cultura kímbùndù. 